\title{
De Santiago Mataindios a Tayta Shanti ${ }^{1}$
}

\author{
Sabino Arroyo Aguilar \\ sabinoarroyo@hotmail.com \\ Departamento de Antropología \\ UNMSM
}

\begin{abstract}
Resumen
En los espacios rurales de Huancavelica, Ayacucho y Junín una de las ceremonias públicas de singular importancia sigue siendo la "fiesta del ganado", "Santiago" o "Tayta Shanty" realizada en los meses de junio, julio y agosto, como espacios y tiempos rituales para la multiplicación de los ganados y de identificación o autoafirmación con los dioses del cosmos andino: Los Apus y Santiago.
\end{abstract}

Palabras clave: Santiago Mataindios, Tayta Shanty, apus andinos

\begin{abstract}
In the rural spaces of Huancavelica, Ayacucho and Junin one of the public ceremonies of singular importance continues being the "celebration of the cattle", "Santiago" or "Tayta Shanti" made in the months of June, July and August, like ritual spaces and times for the multiplication of the cattles and of identification with the Gods of the Andean cosmos: The Apus and Santiago.
\end{abstract}

Palabras clave: Santiago Mataindios, Tayta Shanty, andean gods.

1 Este artículo es un avance del proyecto "Culto al Apu Wamanrasu: Identidad cultural de los pastores altoandinos de Huancavelica". 


\section{La fiesta del ganado es el jubileo de los apus}

\subsection{Contexto festivo y los preparativos del culto}

Junio, julio y agosto son, por antonomasia, los meses de la fiesta del ganado, conocida también como "señalakuy", "Santiago", "herranza" o "Tayta Shanty" en la región centrosur de los Andes (Ayacucho, Huancavelica y Huancayo).

En la cosmogonía andina, la víspera del 24 de junio no sólo marca el inicio de la "Fiesta de San Juan"2, sino, principalmente oficializa la apertura del rito ganadero mediante la "quema de chamizo"3 en el corral o "qatus" de los ganados. Por lo que, la "Gran Hoguera Andina" simboliza el proceso de limpieza del cosmos, fijando el final de la cosecha o del ciclo agrario cargado de malestares o anomalías con efectos sociales y naturales y señalando la "fiesta del ganado" como el período de los ritos de limpieza y propiciación.

En este sentido, San Juan aparece como el personaje renovador del tiempo que señala el comienzo del año de los pastores de los Andes centrales, principalmente. Asimismo, en España de los siglos XVI y XVII, la llegada de "San Juan" señalaba la renovación de los contratos comerciales y el cobro de los diezmos anuales. Ello indica la importancia de San Juan, en la simbología cristiana, dentro de la distribución del tiempo vinculado al solsticio de verano o "culto al dios sol" (y Cristo Dios marca el solsticio de invierno), en sustitución a los dioses precristianos:

"Pero acaso, de todas las festividades del año, la más famada entre los labradores de toda Europa fue la de San Juan, que da lugar a una multitud de refranes y dichos, porque era una fecha señaladísima para ellos desde muchos puntos de vista. Por de pronto, era el 24 de junio el momento de renovar contratos entre amos y criados y el de los desahucios. Es también ocasión de tales expansiones que se dice: "San Juan el Verde no es cada mese". Los clérigos andaban por entonces cobrando los diezmos: "Al clérigo y a la trucha por San Juan le busca". Respecto a las creencias y supersticiones de la noche y al amanecer de San Juan se podría escribir un inmenso tratado con textos antiguos" (Caro Baroja, 1985: 352)

Por tanto, la vida y el pensamiento de los pastores y labradores españoles en los tiempos de la conquista del Perú fueron similares a la actividad de los campesinos y ganaderos peruanos precolombinos, pues desde la colonia y hasta nuestros días, convivieron de manera asimétrica en el juego de hispanizarse o de andinizarse dentro de las relaciones de dominio/resistencia y de contrariedad con ventajas y desgastes para la recreación del universo religioso y estructuración social-étnica, dentro del complicado juego político e ideológico. Así, el día de San Juan se superpone o encubre al día del "solsticio de invierno" (21 de junio) o "Año Nuevo Andino" que marca el final del año agrícola para el descanso reconfortante de los agricultores, después de las pesadas y agotadoras jornadas de siembra y cosecha. Entonces, ahora, renovar el año con el pretexto de la fiesta del ganado es una práctica implícita de demarcar el calendario agrario para proseguir con la preparación de las tierras en las partes altas o con la limpieza de las acequias (Fiesta del Agua) en las zonas qechwas o valles interandinos.

De este modo, la presencia arquetípica de los santos (fecundadores), el jubileo de los apus o la "entronización del rey" (fertilizador) (Eliade, 1968) expresan el concepto del tiempo calendarizado y representan simbólicamente la noción de la regresión del tiempo

2 Antes fue conocido oficialmente como el "Día del Indio" y renovado por el "Día del Campesino". Es uno de los santos más difundidos como el "Santo Patrón" de muchos pueblos en el área andina, mientras en las regiones de la sierra centro-sur del país indica el inicio del sistema ritual ganadero.

3 Del ichu o el rastrojo de la cebada o de la avena o sencillamente encienden la bosta del ganado en las regiones altoandinas, comúnmente identificadas como la sallqa (puna); en oposición a la zona baja o qechwa, donde usan la paja o el rastrojo del trigo para la velación del ganado. 


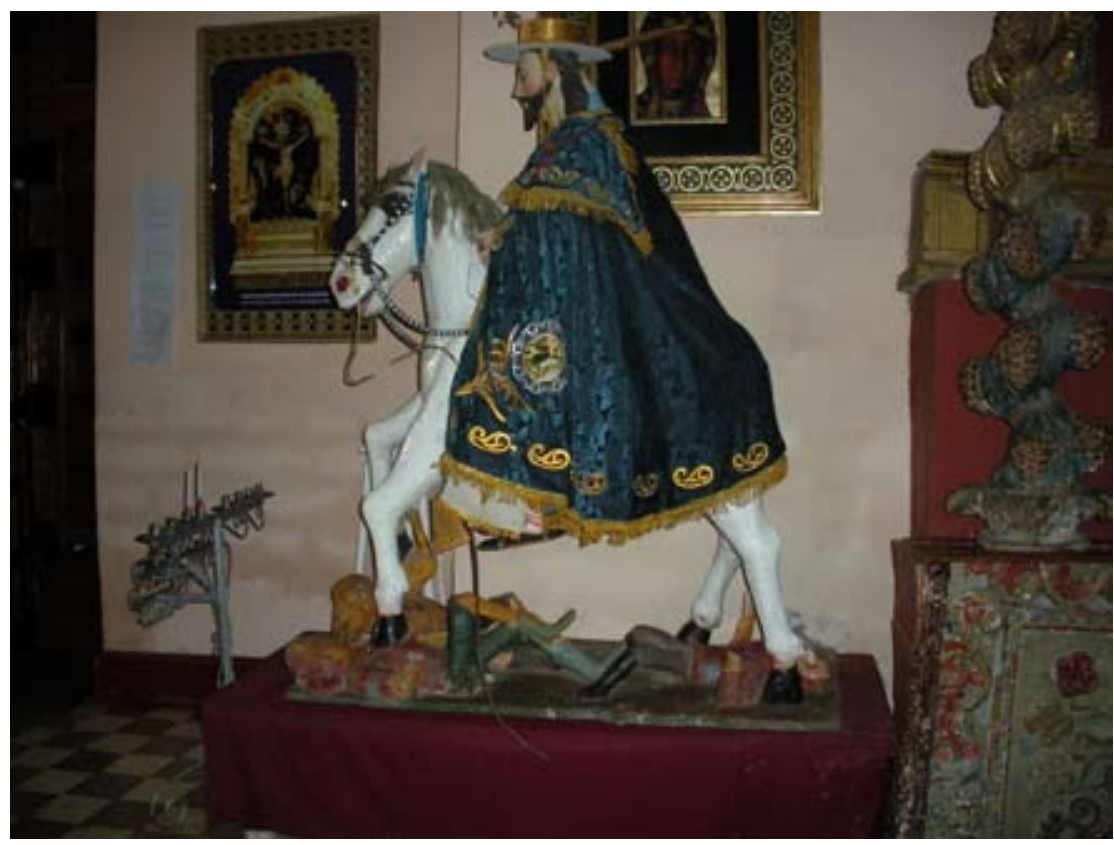

Santiago mataindios de la catedral de Huancavelica.

en estado "embrionario" para su respectiva "maduración". Esto equivale a la siembra y desarrollo de las plantas o al matrimonio y crecimiento de los hombres (marido-mujer) y de las alpacas (hembra-macho), cargado de incertidumbres por las sequías y enfermedades, y también con las alteridades sociales por efectos del poder y conflicto interétnico en el contexto de las ceremonias religiosas festivas. Las mismas que se expresan y se manifiestan en la simbolización de lograr la maduración para la buena cosecha de la siembra, con el riesgo de las heladas y los ganados de los abigeos o de algún acontecimiento perturbador de la naturaleza o de la cultura andina. Una visión no en el sentido fatalista, sino para afrontar y controlar el paso del tiempo social y cultural con sabiduría y ventaja, desde el inicio del nuevo ciclo cargado de nuevas fuerzas o misterios renovadores.

Sin embargo, "San Juan", en cuanto reviste al "Año Nuevo Andino", aparentemente pareciera sólo iniciar el ambiente festivo del "señalakuy", porque la fiesta del ganado propiamente dicha se inicia el 25 de julio y debe concluir indefectiblemente el 30 de agosto. Los días centrales son el 25 de julio (Día de Santiago), el 1 de agosto (Jubileo de los Apus) y el 30 de agosto (Santa Rosa de Lima), consideradas fechas de solemnidad de los "Santos Patrones" y de los "Apu Wamanis". Este ciclo ritual es declarado como la fecha general de festejo, evocación o renovación del compromiso con los pagos (pagapu mayor) a los dioses semilleros, fecundadores de los ganados como son los "Apu Wamanis" (Arroyo, 1987 y 2008) o fundadores de linajes, comunidades o regiones étnicas con dominio territorial, en cuanto son considerados como los operadores del cosmos andino. Por ello, a este ciclo festivo se le conoce generalmente como "Santiago", "Tayta Shanty", "señalakuy", "herranza", "marcación" o la "fiesta del ganado" y antropológicamente como el "rito del ganado".

En la región de Huancavelica, el año 20064, la fiesta de "Santiago" se inició desde el domingo 23 de julio con la compra de los objetos para los rituales por parte de los

4 Los meses de julio y agosto de ese año recopilamos el material etnográfico en las estancias de las comunidades de Santa Bárbara, San José de Astobamba, Choqlloqocha (Choclococha) y en la ciudad de Huancavelica. 
ganaderos de la zona y para este fin, la calle Sebastián Barranca (frente a la Oficina de Relaciones Públicas del Concejo Provincial de la ciudad de Huancavelica) se abarrotó de comerciantes feriantes (trajinantes de ferias y conocedores de la tradición), negociantes de "tienda" o establecimientos fijos y de preocupados comuneros que realizaban sus compras anteladamente. Las tiendas se cargaron de color y olor de las más vistosas hojas de coca, seguido por la llipta (o toqra), cigarro (inka o nacional), aguardiente (alcohol de alquitrán), vino, pisco, cerveza o coñac y variedad de gaseosas, galletas animalitos, caramelos, etc. Mientras los comerciantes trajinantes expenden sus productos en el piso de las calles sobre sus mantas con hule, ahí encontramos en muchos puestos el níspero (fruto símbolo de abundancia para la wallqa o regalo de los ganados y pastores), las cintas multicolores como las flores del campo (lima-lima wayta y qoriwayta que propiciarán multitud de colores de los ganados) provenientes de Waytapallana (cerro y apu mayor de Huancayo) y los claveles de los huertos familiares. También las solícitas "tinyas" (tambor pequeño de cuero de ovino y camélido tierno o de preferencia del zorro, tigrillo o venado con propiedades de la buena suerte) de distintos tamaños, hechos en la región y que nunca faltan en cada casa en la fiesta del ganado. Su festiva importancia es notoria, la tinya es la compañera inseparable de los participantes y de fácil manejo para acompañar las más hermosas y emotivas melodías cantadas con sentimiento por las muchachas o reproducidas por las infaltables grabadoras de cintas o de $\mathrm{CD}$, que reemplazaron a los tocadiscos, para ambientar la fiesta entrecortados por los grandes guapidos y zapateos como también para acompasar hasta el más simple tarareo del alegre pastor que no deja de rodear a sus alpacas por mantenerlas siempre juntas en el centro de la cancha o cerca de la mesa ritual.

Este nuevo ciclo festivo del ganado no sólo significa el rito de propiciación para la multiplicación de los ganados, sino para ratificar el compromiso con el "don" de los apus, a manera de renovar el contrato o débito, así como para reafirmar los valores culturales de cohesión del parentesco (consanguínea, ficticia o espiritual) y ocasión para nuevas estrategias de alianzas y formas de socialización andina; incluso, es el tiempo de renovar el dominio implícito del espacio ritual del hombre en las estancias matrilocales o neolocales.

\section{2. "Paqo Señalakuy": rito de la alpaca.}

Los preparativos de la fiesta ganadera se realizan con el presuroso recojo y acorralamiento de los paqos ${ }^{5}$, llamas y algunos ovinos en las respectivas canchas de cada familia alpaquera, precisamente para el inicio del rito con la "quema de los chamizos" de bosta y del ichu a partir de las seis de la tarde. Esta "quema del chamizo" sirve para la purificación del mundo andino ya iniciada desde la noche de "San Juan", donde las hogueras en los Andes anuncian el inicio explícito de la "fiesta del ganado", rito esperado durante el año con tanto anhelo y ansiedad, aunque signifique problemas financieros y de asuntos cotidianos a las familias y comunidades.

Luego de la parafernalia de fuego e incienso del ichu y de la bosta, la noche ritual se inicia con el arreglo de la "mesa ritual" y con ella se oficializa la "mesa velakuy" (velar en la mesa los objetos rituales) en la misma despensa o en el corredor de la casa, después

5 "Paqos" o "alpacas", nombres genéricos en la región de Huancavelica; los monolingües del español usan más el término alpaca y los quechuahablantes usan paqo. Desde los últimos 50 años se da mayor importancia a la crianza de las alpacas porque su fibra (de exportación) significa "plata" (mejor ingreso) y la crianza de las "llamas" está reduciéndose sólo para el transporte o de uso familiar (la carne y la fibra para costales de carga). 
del suculento "caldo de paqo" con sus yapas para calmar el hambre y resistir la noche de velación. La "mesa ritual" se realiza entre las 8 y 9 de la noche, cuando los miembros de la familia (no siempre todos asisten) y los invitados ya están ubicados en sus respectivos sitios, ya sea sentados o recostados sobre la abrigada cama de coposos pellejos y jergas pesadas de alpaca o de llama tendidas en el piso, precisamente al frente y en los laterales de la "mesa ritual". También la "mesa" está cargada de objetos rituales que rodean a la imagen de "Tayta Shanti" o "Santiago" (un cuadro) y de la "cruz de ichu" (representa al apu), y en la parte delantera y central están las "illas" de los paqos depositadas en pequeños mates; también está el llampu y las flores del campo que no deben faltar. Entre las variadas y coposas flores silvestres que rodean la mesa está la "sorasora" traída de la montaña Wamanrasu, y la "limalima wayta" del cerro Qanampalla.

Entrevistamos a don Zósimo Hilario Quispe y a su esposa, Áurea Torres Huayhuani ${ }^{8}$, quienes son el apoyo principal de la viuda y anciana doña Honorata, y nos dicen que desde ahora don Briselio Torres (hijo menor casado) se encargará de organizar y dirigir los rituales de la velación, con el pagapu del apu y el señalakuy de los paqos. Así lo habría hecho en vida su padre como jefe del hogar y luego el hijo mayor que ahora tiene su nuevo domicilio en la estancia de su esposa (residencia avunculada) ${ }^{9}$. Las ceremonias siempre fueron dirigidas por los hombres mayores y, en este caso, el hermano mayor no llegó a tiempo por vivir en otra estancia alejada, por lo que implícitamente le sucedió Briselio, con el apoyo y orientación de su amigo y cuñado Zósimo.

Para el preparado del "llampu" se trajo "aqno", "unu"10 o el agua sagrada desde la cabecera de la laguna Manchayqocha (laguna temeraria o poderosa con encanto). En ese contexto interrogamos que si todavía traían "agua del mar" para estos casos. Y la respuesta inmediata de doña Honorata fue la reafirmación de que nunca había escuchado ese caso para la fiesta de los paqos o de las llamas, en cambio para la fiesta de los vacunos sí habrían traído desde Lamarqocha en los tiempos antiguos y nos precisó que: “[...] para las vacas han traído de Lamarqocha, juntos han venido". Con ello marcó distancia y clasificó con precisión que el ganado vacuno llegó de la costa, con clara alusión al proceso de la conquista y formas de colonización en oleadas del norte al sur o de la costa a la sierra y relacionó

6 Cada familia sacrifica uno o dos paqos para la fiesta (antes del 25) o para la atención holgada de la familia e invitados que llegan cargados de regalos y recuerdos de familia.

7 De diversas formas, colores y tamaños, simbolizan a los machos, hembras y sus crías. Las illas son espíritus reproductores encarnados en las piedras modeladas en forma de paqo, llama o carnero con aspecto preñado o esbelto. Ello indica que hay illas hembras y machos para la multiplicación y perpetuación de su variedad y en tanto son espíritus, son los ganados o los representantes de los apus de su jurisdicción.

8 Ella nació en esta estancia y sus padres son don Ricardo Torres (finado) y doña Honorata Huayhuani, quien es la patrona y la figura central de la fiesta, pero no puede dirigir el ritual, como la costumbre ordena, y sólo ayuda a alcanzar y precisar el manejo de los elementos rituales durante el tendido de la mesa y en los preparativos de la ofrenda para el pagapu al apu de su hatus.

9 Sin embargo, llegó al día siguiente (26 de julio) con todas sus alpacas y en el mismo redil de su padre realizó otro "señalakuy" en respeto a la tradición patrilocal, en relación a su procedencia y el origen de los camélidos semilleros, sino acarrearía desgracia general.

10 Es el término de uso frecuente en la región de Cusco para denominar al agua sagrada sacada del ojo de agua o del manantial para las actividades de la fiesta del agua; también el término "yaku" significa agua, y es de uso frecuente y común para el quechuahablante. En cambio, en las regiones de Ayacucho y Huancavelica se usa exclusivamente el término "aqno" como agua sagrada del manantial y se encuentra asociada a los lugares de pastizales circunscritas a la juridicción de sus apus locales. Esto confirmaría la permanencia de algunos términos rituales sureños en los inmigrantes históricos y étnicos, así la señora Honorata Huayhuani nos dijo que sus ancestros fueron originarios de Cusco (ver en los apus mayores con poderes y relaciones interregionales). Además, ella tararea el santiago (canción) y entre algunas letras guturales no entendibles de su canto (por la improvisación o libre expresión, entre la memoria y el recuerdo de los buenos tiempos), pronuncia con claridad los términos "aqno" y "unu”, exclusivos en la actividad del tiempo ritual. 
con las cualidades del mar, indicando simbólicamente, como de origen transoceánico o venidos de España y, es más, nos mostró las preferencias y sus cambios, que: "Únicamente Lamarqocha tiene las perlas y sólo las vacas tienen los arete de las perlas". Lo que indica la preferencia por los ganados vacunos en reemplazo a los camélidos, por constituir el brazo del campesino agricultor y del ganadero comerciante.

Según el reloj moderno, controlado por Zósimo, se acerca la medianoche esperada y de inmediato se procede con el chaccheo de fondo y más consistente que los anteriores, todos concentrados en el "pagapu" principal para el apu de la familia, y en esas circunstancias, doña Honorata inicia el rito con los cánticos en alusión al tiempo y al retorno del ciclo ritual:

"Ñachum-ñachum horanña, ñachum-ñachum tiempunña Señorllay Apu Wamani, Señor Qapaq Santiago" (Parece que ya es la hora, parece que ya es el tiempo mi Señor Apu Wamani, Señor Gran Santiago) ${ }^{11}$.

Briselio empezó a juntar los elementos rituales del pagapu mayor de manera ordenada en un mantel blanco, bajo la ayuda e indicación de Zoísmo (únicos en la mesa ritual ante nuestra mirada atenta a distancia), sin que la mamá, la hermana o alguien se acercaran o pronunciaran algo considerado impropio y amonestado con severidad. Así como agruparon sigilosamente, también con cautela salieron los dos, oferente y ayudante, en completo silencio y luego, la mamá Honorata nos afirma que, para la eficacia del pago o para ser aceptado por los apus, no debe haber ningún ruido, ni el ladrido de los perros. Envueltos por el frío delirante y azotados por el viento lacerante de la puna, los oferentes, "bien animados" (con trago y cigarro, portaron otra botella de cañazo llamado "fiambre", como ánimo para enterrar la ofrenda o "despacho") desaparecieron en la noche estrellada rumbo a la mesa del corral, ubicado justamente debajo del pequeño cerro Palomo, residencia del apu de la familia Torres-Huayhuani.

Al cabo de unos 45 minutos el retorno de los oferentes constituyó la gran algarabía, recepcionados con abrazos y palabras rogativas, alegría de familia que ansiosos esperaron el buen resultado del pagapu; y luego, todos retornamos a nuestros respectivos sitios en el espacio ritual para continuar con "mesa velakuy", y en este caso ya es libación de alegría a nombre de los apus y Santiago hasta el amanecer, animado por la "música de santiago"12 que emitía la grabadora y acompañada o reforzada por las sonoras canciones de la señora Áurea (hija de la patrona dueña), cargadas de evocaciones por los mejores tiempos (como negando a las incertidumbres de hoy) y también animados por los enérgicos guapidos del esposo y de los primos, de cuando en cuando. Así se abrió el contexto festivo familiar y comunal, detonante y total. Lo que indica que con el pagapu de medianoche se logró la licencia de los apus y la apertura del "señalakuy" o "santiago" para la gran fiesta de cohesión familiar con sentido identitario étnico, donde todos participan cantando, bailando o tomando hasta el "señalakuy" (en el mismo corral ancestral).

Luego del descanso matutino y almorzar el apetitoso mondongo, se reparó la flaqueza y la resaca; nuevamente todos se aprestaron para el "señalakuy de los paqos", alistando otra "mesa señalakuy" en el mismo redil de las alpacas y dándose por reiniciado con la distribución de la mama coca, toqra (símbolo masculino) y cigarro a todos los participantes, distribuidos en dos mitades por sexo: los "patrones" (elevados a esta categoría sólo para el

11 Canto ritual que indica la llegada de la hora de los preparativos para el pagapu mayor de las ofrendas de la mesa ritual y momento en que los oferentes inician a juntar los elementos necesarios de manera sigilosa como para no perturbar la memoria colectiva.

12 Entre los géneros de la música andina, además del harawi, wayno, waylas, hachwa, chonguinada y carnaval, el "santiago" es un término génerico y específico para designar a la música de la fiesta del ganado, ejecutados por los artistas de la región. 
contexto festivo) se colocaron a cada lado de la "mesa", el "patrón" (esposo) ocupó el lado derecho seguido por todos los varones grandes y chicos. De manera similar (en simetría) la "patrona" (esposa) se colocó al lado izquierdo seguido por todas las mujeres.

Esto indica que los "patrones" cumplen el papel clasificador de la división complementaria del sexo y de cohesión familiar, según el orden y grado del parentesco o afinidad; aunque de cuando en cuando se desestructura el orden y la correspondencia para compaginar y reforzar la jerarquía estamental con la relación asimétrica (los brindis y diálogos familiares y amicales por los migrantes de visita, así como con el chaqo ${ }^{13}$ de los paqos y la danza en parejas); aunque el rango no se altera durante la colocación de las cintas a la pareja de paqos jóvenes, como modelo ritual de la hierogamia cósmica replicable que propicia la fertilidad y garantiza la multiplicación de los ganados del ande. Esto indica que la fiesta del ganado es una actividad específica y totalizadora en la racionalidad andina, una relación ritual vital, generadora y renovadora de manera constante del universo biológico, de la economía reproductiva y de la estructura familiar, comunal y social.

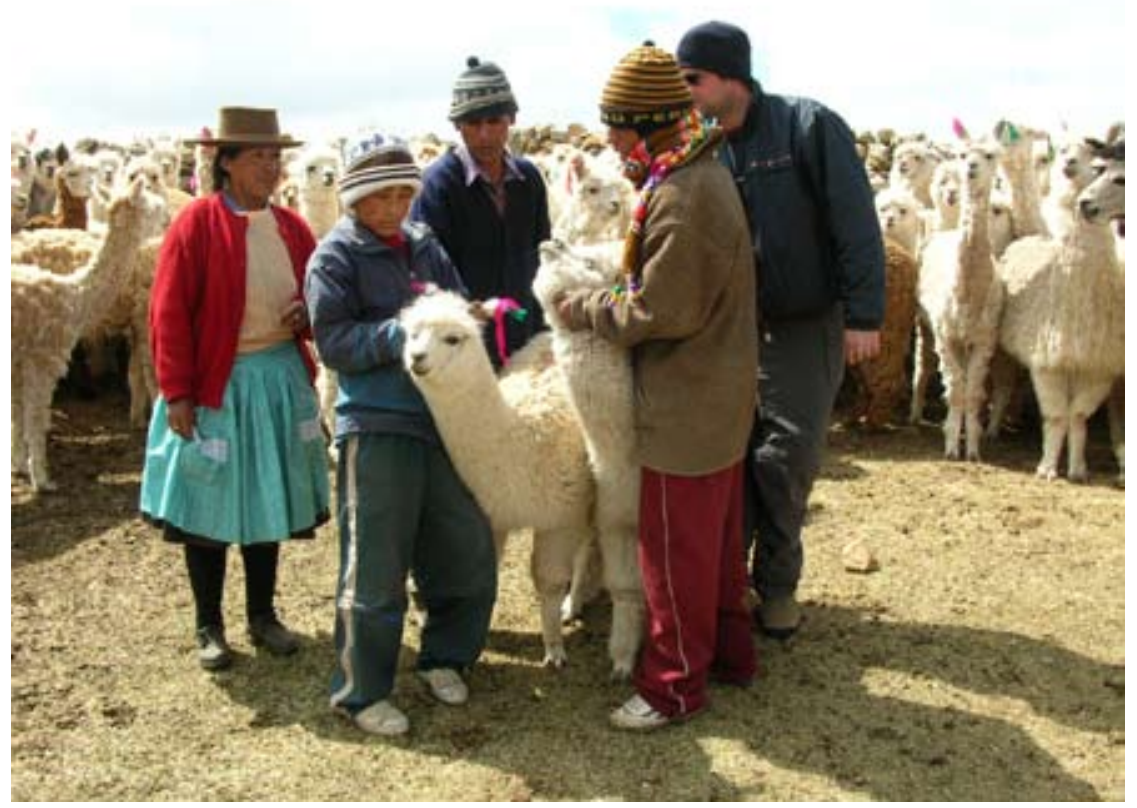

La hierogamia de los paqos jóvenes.

Es significativa la secuencia del acto ritual del "señalakuy", donde el "patrón" escoge a su ayudante de confianza que se encarga de distribuir la infaltable "mama coca", el cigarro,y su toqra y, de cuando en cuando, convida el trago; de igual forma la "patrona" encarga a su representante con igual función. Esta distribución y clasificación asimétrica sólo se alteran o entrecruzan en el momento del inicio del emparejamiento de los paqos jóvenes, del señalakuy (colocar la cinta) de las demás alpacas y en la despedida, que significa la unión y complementariedad dentro del principio y de la organización dual del espacio vital y de la estructura familiar. Estas dos mitades simétricas de pareja hombremujer y su condición biológica, social y cultural guardan correspondencia con la estructura

13 Es el acto de atrapar a los paqos rompiendo la manada dentro del corral, según la selección de los patrones, sea para emparejarlos o para la colocación de las cintas respectivas. 
simbólica del sol-luna, día-noche, hanan-urin, derecha-izquierda o del patrón-patrona, explicitados por el emparejamiento especial de los jóvenes paqos macho y hembra durante el señalakuy.

Asimismo, este contexto festivo clarifica la función del día y la noche en el mismo sentido dual y correlativo o se replica la fusión de los espacios sagrados y profanos con los tiempos rituales, la "mesa velakuy" de la víspera en la casa y el "pagapu" al apu familiar, a medianoche, con el velakuy diurno en la "mesa corral" y su conclusión con el "señalakuy" (colocación de las cintas a los paqos) en el propio redil. Los "patrones" o los dueños, con el afán funcional y sentido de pertenencia, buscan reafirmarse en el juego asimétrico del tiempo y espacio sagrado y profano, dentro del aspecto de oposición y complementariedad de la residencia de los dueños y el redil de los ganados y la jerarquía de los apus con la estructura familiar y comunal. Y es cuando el tiempo y el espacio se hacen críticos porque los apus pueden adelantarse de noche con el "señalakuy" cuando oportunamente no se le recuerda con la "mesa velakuy" como con sus pagos en el momento establecido (acarreando desgracia a los ganados y a la familia); asimismo el de día, el "señalakuy" y el emparejamiento de los paqos es de extremo cuidado y de especial dedicación por los dueños, para lograr la eficacia del rito esperado para la multiplicación de sus camélidos, que antes significaba prestigio del buen pastor o ganadero y ahora ya es dinero o inversión.

Esta actividad organizacional y actitud ritual justifica la estructura social jerarquizada para el ordenamiento de las organizaciones campesinas (sistema de autoridades, poder y conflicto) con el afán de regular el sistema comunal estamental para su extensión, pese a las continuas innovaciones y variaciones funcionales del estatuto de las comunidades campesinas promovidas por el Estado, al margen de las tradiciones culturales y productivas. Lo que explica la vigencia de las comunidades andinas con sentido identitario y principio territorial, que descansa en el paradigma de la estructura de los apus locales y regionales, como una racionalidad del sistema ecológico. El hombre y la naturaleza no sólo se autorregulan por el control y dominio, sino también interactúan y se integran para respuestas y direcciones sustentadas con ventaja integral, como dos protagonistas en la simbología del drama universal en mutua alianza, oposición y convivencia en perspectiva.

\section{De Santiago Mataindios a Tayta Shanti pastor de los ganados}

En el lado derecho ${ }^{14}$ del acceso a la iglesia matriz de la ciudad de Huancavelica se encuentra la imagen de "Santiago Mataindios" con vestido celeste y capa roja decorados con hilos de oro, sombrero blanco huancavelicano a la pedrada y reluciente como un guerrero ${ }^{15}$ fogoso con espada desenvainada que atropella o abate a tres "indios" que yacen entre los cascos de su hermoso y brioso caballo blanco (dos entre las patas delanteras y uno por las posteriores); así, mostrando que también se ensañó con furia y ventaja contra los nativos andinos, en son de la "guerra a los moros" en la reconquista de España y por la "religión cristiana" en contra del "islamismo" o del "paganismo" de todo pueblo o civilización de otra cultura y religión.

14 En la visita del 24 de julio de 2006 hallamos la imagen de Santiago en dicho lugar, pero el 11 de febrero de 2009 encontramos la imagen en la parte posterior del separador del acceso central ya con capa azul, como denotando que controla o supervigila el ala derecha del atrio matriz para continuar hacia el interior y observar las hermosas y ostentosas hornacinas de pan de oro al estilo barroco.

15 Esta representación de Santiago que encontramos en la catedral de la ciudad de Huancavelica es parte del trabajo de campo de la mañana del 23 de julio de 2006 y responde precisamente al símbolo colonial cristiano de Santiago como un personaje arquetípico de un Santo Patrón de España, que siempre invocaban los soldados españoles para entrar a la guerra de reconquista de sus tierras ocupadas por los árabes y generalizándose después en la conquista de nuevas tierras en América, en este caso en el Perú. 


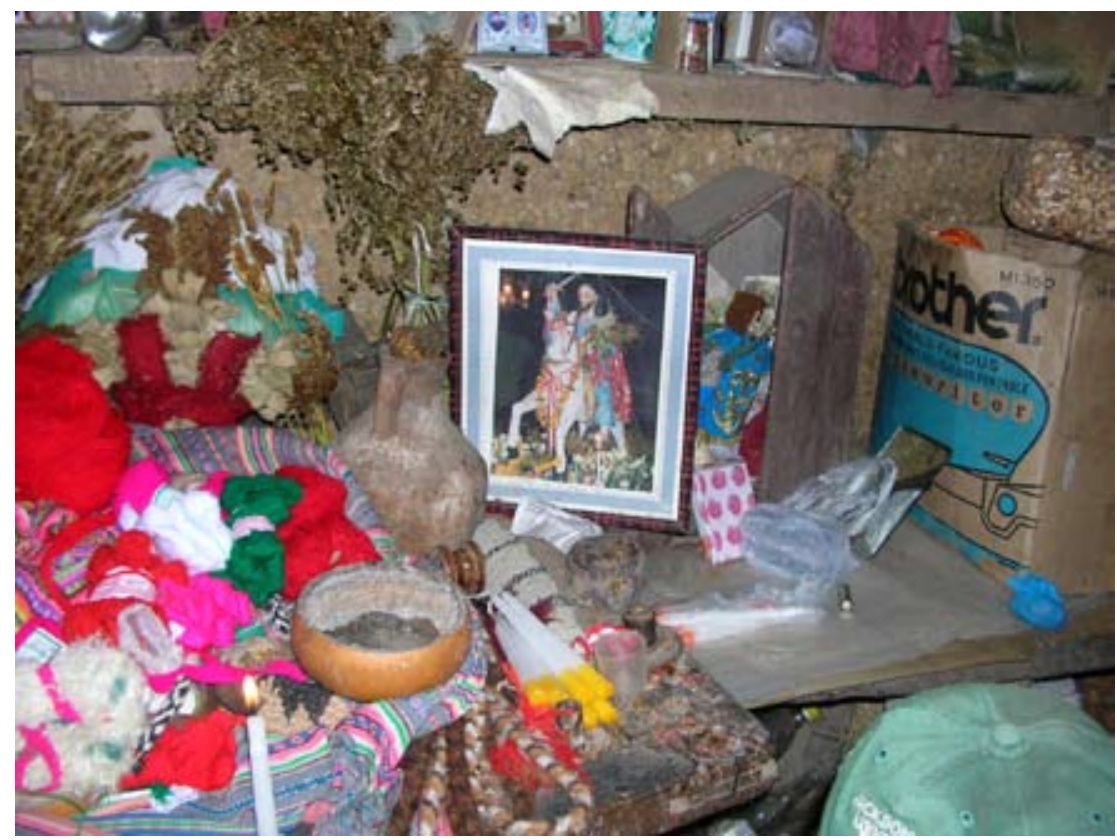

La mesa ritual de los paqos en Titiqasa.

Con el paso del tiempo, esa imagen de "mata indios", por favorecer o ayudar a los "chapetones", quedó en el olvido o en la ignorancia para la generación actual. De modo tal, cuando visitamos al templo principal de la ciudad de Huancavelica, en una de las mañanas cercana al 25 de julio, encontramos a muchos lugareños (ganaderos o pobladores urbanos) arribar presurosos al templo, para ofrecerles cirios, flores y oraciones, muy devotamente, y acto seguido, también solicitarle la bendición y protección de su familia y especialmente, por la salud y multiplicación de sus ganados, en este mes ritual de julio, identificado como el mes de la "fiesta del ganado" o de "Tayta Shanti", para la actividad intensa de los campesinos agroganaderos de las regiones andinas del centro-sur.

Esta misma imagen de Santiago la encontramos en la casa de la anciana Honorata Huayhuani en Titiqasa, en un cuadro de $20 \mathrm{~cm}$ x $30 \mathrm{~cm}$ (es el retrato del santo de la catedral) y que ocupa la parte central de su "mesa velakuy"; por lo que a la primera vista, pensé en la figura central del ritual y de la fiesta del ganado y mientras, la representación del apu no percibí en ningún lado de la mesa.

En la estancia de Titiqasa y en la región de Huancavelica es común saber y describir la figura del apu Wamanrasu. Se dice que es un gran caballero blanco y barbudo que cabalga su brioso caballo blanco en la víspera de "Santiago", puesto su macora (sombrero blanco) grande y su poncho de vicuña. Y es curioso lo que afirma la muy noble y celosa guardiana de la tradición, doña Honorata, cuando asegura que:

"Paija, hatun yuraq caballompis sumaq qollqe bridayoqwan purin santiago tutapi, ñam kaypiña wakpiña achkallaña purichkanku. Kunallan ratom ñam juntallaña purikuchkanku, ñacha kaitapas pasarunña. Apukunaqa wasita yaykurinku hawanankupaq ñachum mesa velakuypi kachkanku, chaysi paykunapas kusikunku, manachayqa hatun castigoyuqmi kanku. Apukunaqa invitanakunkum vinuta champanta hatun punchawninkupi".

(Traducción) 
"Él (Apu), en su elegante y gran caballo blanco con brida de plata cabalga en la noche de Santiago, seguramente ya estarán muchos de ellos por aquí y por allá. En este momento muchos de ellos ya deben estar en todos lados, seguro ya pasó por aquí (por su "mesa velakuy"). Los apus ingresan a las casas ${ }^{16}$ para saber si ya están en la velación de la mesa, por eso también ellos se alegran, sino son muy sancionadores. Los apus brindan en su día con vino y champaña".

En circunstancias de mayor veneración a los apus por la familia Torres-Huayhuani, en la víspera de "Santiago", interrumpí para preguntar cuál era la diferencia entre la devoción a "Tayta Shanti" con relación al culto de los apus. Al respecto, con mucha tranquilidad reaccionaron de inmediato y la señora Áurea intervino mostrándome los elementos rituales componentes de la "mesa velakuy", en los siguientes términos:

Kayqaya qawasqayki hina, paypas kachkan yuraq caballuchampi qori-wayllayoq, santiago waytayoq, fruta wallqayoq (plátano, díspero, manzana)”.

\section{(Traducción)}

Aquí está, como usted mismo puede ver, también él (Santiago) está en su caballo blanco con su wayllay de oro, flor de santiago, rosario de frutas (de plátano, níspero, manzana)".

Y en ese momento su madre (doña Honorata) interrumpe enfáticamente para precisarnos su percepción sobre algo que no podía dejar de pasar, un concepto codificatorio y formas de representación de dos imágenes e iconos con distintos orígenes que compartían indistintamente, con apariencia confusa o entremezclada por su arraigo y sentido del culto; como nos dice:

"Kaypiñas, taytay, waktaqa ruwasqakuqa. Payqa mana wallqayoq, mana imayoq purikusqa. Kaypiñan misachispanku chaykunataqa ruwarunku santiagopiña, ñoqanchik hina runakunaña. Payqa Rayutam qarqochkan, Satanastam qarqochakan, paymi cuidawachkanchiq". Kunanqa ñam costumbriña, imaynam ñoqanchiq tusunchik wallqayoq. Chaynatas mama Justi (Justina) ruwachimosqa, chaynatam willakurqa tayta Maxi”.

(Traducción)

"Ya fue aquí, señor, lo que eso hayan hecho. Él (Santiago) deambuló sin su adorno, sin nada. Ya fue aquí que mandaron hacer su misa y adornaron en santiago (fiesta), la gente como nosotros. Él (Santiago) siempre está ahuyentando al rayo, a Satanás, él nos está cuidando. Ahora ya es costumbre, así como nosotros bailamos con los adornos. Así había mandado hacer mama Justina, contaba así don Maxi".

Sin embargo, casi como contradiciendo, prosiguió doña Áurea comparando y reafirmando que el modelo está como la imagen de "Tayta Santiago" que se encuentra en la puerta de la catedral de la ciudad de Huancavelica: "con su wallqa (adorno) y con su wayllay (ichu de oro)". No obstante, su madre insistió que no era así cuando ella vio no hace mucho; pero el yerno reafirmó lo dicho por su esposa y así quedó la idea, aunque no satisfizo a doña Honorata. Entonces, la anciana no convencida justificó que seguramente están realizando su misa por su día. En eso, Briselio atestigua que el "Tayta Santiago" está con la banda de una cinta peruana (blanquirroja). Al final, el debate concluyó con el porfiado testimonio y aseveración de la octogenaria en los siguientes términos: "Puntataqa manam chaynachu karqa, kay qepakunañam novenanmanta wallqachichkanku. Kunan kay, paqarinmi hatun punchawnimpi misan qanqa". (En los tiempos antiguos no era así, ya en los tiempos recientes, desde su novena, ya están adornando. Pues bien, mañana en su gran día harán su misa).

16 La noción es que todo los apus trajinan esa noche y esto se asemeja a que en otros lugares (en el sector de Acobamba) los jóvenes se organizan en comparsas para pasear y visitar a las casas de los oferentes o dueños de la "mesa velakuy", donde bailan al compás de las quenas y de las tinyas. 
A pesar de esta descripción asociativa y un tanto diferente, para mayor claridad insistimos con la pregunta directa: ¿mañana es también día grande del apu Wamanrasu? La respuesta fue afirmativa y unísona, precisada por doña Honorata, quien incidió con la generalización siguiente: "Paqarin punchawqa qalay-qalay Tayta Orqukunapa santunmi" (El día de mañana es el santo de todos los Padres Cerros -Apu Wamanis-). Luego continuaron risas sobre mi carencia en distinguir a los dos personajes, quizás un tanto absurdas al peso de la tradición y de las prácticas rituales de la noche parafernalia, vigorosa por cierto al paso del tiempo. Para revelar y reafirmar lo que se vive la víspera del cumpleaños de los apus, la octogenaria prosiguió con sus cánticos de Santiago y guapidos al compás de su tinya en mano.

Entonces, el 25 de julio es el día grande del Apu Mayor Wamanrasu y de todos los apus del mundo andino; y itambién del "Tayta Santiago"? Es evidente que un pequeño cuadro con la imagen de "Tayta Santiago" sobre su caballo blanco ocupa la parte central, entre la "Cruz del Ichu" y las "Illas" que representan al apu de la localidad o a los apus de la región. Según la cosmovisión lugareña, los apus recorren, de casa en casa o de familia en familia, estancias y pueblos, aquí en la tierra o "kay pacha", y ven lo que sucede y saben quienes les recuerdan o cumplen con su deber efectivamente desde su noche (víspera); mientras, "Tayta Santiago" sólo se presenta (en el cuadro) en la mesa ritual como en este mundo, ya que personalmente se encontraría lejos o en "hanaq pacha" (mundo de arriba), para cuidar a los comuneros en riesgo de ser engañados por el "Diablo" o de ser alcanzados por el rayo que se produce cuando Santiago dispara a su eterno rival y sucede que en las alturas siempre está disparando sin lograr su cometido. Por eso, cuando alguna persona es herida o muere por la acción del rayo, se justifica como accidente ocasionado por la Tayta Santiago en su eterna persecución al diablo.

Para la población altoandina, los relámpagos y truenos o la "llipia" (¿"Illapa"?) son de sumo cuidado, porque existen innumerables casos de personas o animales impactados (heridos o muertos) por los efectos del fenómeno meteorológico, que se producen frecuentemente en las mesetas o cuencas de altura por encima de los $4000 \mathrm{msnm}$. Por ello, en toda la región de altura de Huancavelica, Santiago es identificado como el santo especializado y muy ocupado en perseguir al "Diablo" con su arcabuz; entonces, el trueno o el rayo de día o de noche es relacionado con el disparo de la escopeta (arcabuz) y por consiguiente, Santiago es conocido como el "cazador del diablo", así como los "mistis", con su carabina, son cazadores de vicuñas, vizcachas o venados de las alturas. Además, para la población rural existen dos tipos de rayos y truenos: primero, cuando se escuchan los truenos en la dirección de las montañas sagradas significa el anuncio de la proximidad del invierno y cuando el trueno es continuo con muchos rayos llega la temporada de lluvias para la siembra mayor del año, por eso en la sierra central el mes de enero es conocido como "enero loco" ${ }^{17}$ por la intensa y fuerte precipitación pluvial (día y noche); segundo, la

17 Hasta los años setenta, aproximadamente, fuimos testigos de la "buena lluvia de siembra" que consistía en la intensa lluvia que se producía entre rayos, relámpagos y truenos. Por ende, habían muchas lagunas, ríos crecidos y cantidad de manantiales y oconales que servía para la buena cosecha y abundancia de pastos para todos los ganados de la zona qechwa y altoandina. Y toda esta abundancia de la madre naturaleza proveedora viene desapareciendo gradualmente y acelerándose en los últimos tiempos, que ocasionan el desecamiento de las fuentes de agua y la escasez del forraje. Es más, para la honda preocupación de los pueblos y autoridades locales y regionales se produce también la "fiebre de los nevados", porque el nevado Wamanrasu y algunos otros muestran su escaso casco de hielo y los oconales de sus praderas están en secamiento, con poco forraje y famélicos ichus que peligran la vida de las "vicuñas ariscas", muestrario del camélido sudamericano. Ya pasó la época cuando muchas montañas de la sierra se dibujaban de nieve y en especial en su temporada de friaje (caída de hielo) desde mediados de mayo, junio, julio y parte de agosto. La montaña Rasuwillka ya perdió su nieve por completo y muy ocasionalmente se cubre en su temporada, igualmente el nevado de Qarwarasu del sur de Ayacucho se deshiela como el Wamanrasu de Huancavelica. ¿Dónde estarán los apus y qué harán? 
presencia del rayo que preside al trueno y al invierno es "malagüero" porque anuncia mal tiempo o mala cosecha del año por falta o escasez de lluvia y por eso le conocen como el "chaki rayo" (rayo sin lluvia) o espíritu malo.

Este fenómeno meteorológico clasificado y personificado en dos protagonistas con cualidades contradictorias, en oposición, probablemente fueron elevados como espíritus o deidades dicotómicas y por consiguiente, en la cosmovisión andina, el Santo Patrón Santiago reemplazó al "Rayo Bueno" que ahuyenta al "Rayo Malo" en la figura del "Diablo", mientras en las zonas bajas ocupadas por los campesinos o comunidades rurales descendientes de las haciendas coloniales, en los departamentos de Huancavelica y Ayacucho, definitivamente "Santiago" es el patrón de los ganados vacuno, caprino, ovino y caballar. Esto marca el ciclo de echar cintas y marcar los ganados para su identificación en casos de pérdida o de abigeato, y también es pretexto de algarabía festiva para el reencuentro familiar. Y sin embargo, el proceso de contacto entre dominio y resistencia, y de mestizaje con la población andina de origen precolombina, también ha producido ese proceso de andinización o indianización.

Por consiguiente, la duplicidad de funciones o semejanzas de cualidades de los santos con los de los apus, no constituye en modo alguno problema de intromisión o de exclusión, sino, en cuanto ambos cumplen sus respectivas funciones, es más gratificante y garantía ampliada para la seguridad y economía de las familias pastoras de altura de la región. Es decir, los "apu wamanis" y el "Tayta Santiago" o los santos conviven, se complementan y comparten el culto y los ritos del 25 de julio o en toda la temporada de la "fiesta del ganado" (de junio a agosto). Es más, los santos fueron reinterpretados con la lógica andina, por lo que la autoridad y el poder de los apus son vistos en la imagen de los Santos Patrones. Además, la presencia y función de Santiago es más temporal asociado al ciclo ritual ganadero del año (de junio a agosto); mientras, la presencia de los apus es permanente y en todo momento (de día y de noche) y en toda circunstancia de la vida cotidiana del campesino. Lo que explica que estamos frente no de un apu único, sino de muchos ${ }^{18}$, como tantos pueblos existen y legitiman ser sus gentes o sus descendientes directos desde tiempos inmemoriales y por "tradición" se practican o se repiten tantas veces sea necesario recapitular los honores que se tiene y se debe, dentro del contexto festivo o "santiago" y de la repetición del rito consagratorio de propiciación para la multiplicación de los ganados.

Así, los apus están siempre presentes y más cerca de ellos con sus respectivos rangos. Tienen sus apus de familia y de la estancia, de la zona y de la región; pueden trasladarse a otras estancias o comunidades circunvecinas. De acuerdo a los apus se identifican parientes o se consideran como buenos vecinos dentro del sistema de reciprocidad social, no existe exclusión y peligro, sino se amplía y se incluye el resguardo al forastero en condición similar; en su defecto y para mayor garantía, está la presencia del Apu Wamanrasu que se ve y se proyecta hasta más allá de sus confines, como un ente ordenador y operador en toda la jurisdicción de Huancavelica. El Apu Wamanrasu es considerado mayor ${ }^{19}$, famoso y respetado por ser más conocido que los demás. Desde esa perspectiva, representa a los pastores, agricultores y comerciantes o a toda la población huancavelicana que se identifica o se considera como miembro integrante con mayor espacio de dominio; y por consiguiente, en cuanto comparte y se equipara con otro apu homólogo de otra región,

18 Todos ellos considerados dentro de la jerarquía del parentesco (hermanos mayores o menores, padres o hijos, esposas o esposos o abuelos, hijos y nietos) y, por la misma razón, también los santos patrones aparecen estructurados a imagen y semejanza de los apus (Arroyo, 2008).

19 En cuanto a la altitud, el nevado Wamanrasu (5298 msnm) es menor a la altura del nevado de Citac (5328 msnm) de la comunidad de Ascensión; sin embargo, cultural y religiosamente el apu Wamanrasu goza del reconocimiento general como representante e icono de Huancavelica. 
es considerado dentro del modelo de parentesco (hermano mayor o menor, padre, hijo o nieto), sus relaciones y competencias se rigen dentro de la estructura del poder parental para garantizar la condición social y étnica de las comunidades andinas.

Es más o cómo explicar el hecho cultural y religioso, que tanto los apus como el Santiago no sólo tienen su respectivo caballo blanco; sino y al parecer, en el mundo de la competencia, los apus tienen los mejores corceles de "pura sangre" con los aperos adornados de plata y que muy gallardamente recorre su dominio en la víspera y compiten con otros de su mismo rango de otras regiones. Entonces, presentan a los apus en sus mejores caballos que el Santiago; aunque, los pobladores altoandinos poseen caballos menudos clasificados como "chuscos", por la presión de la altura y carencia del forraje (sólo hay el ichu y gramalotes) para los "caballos finos" o quebradeños del valle (con abundancia de alfalfa y pasto verde).

Esta simbología de inversión a manera de compensación o de perspectiva alternativa, responde a la contradicción social y cultural del contexto como resultado a los hechos históricos de dominio y coloniaje o de poder y servidumbre que condujo a formas de resistencia y condición de existencia, donde la adaptación del caballo o de las acémilas fueron efectivas, como los ganados vacunos y otros ganados para la economía agraria y la organización de las familias campesinas andinas.

En la psicología del campesinado, la eficiencia de las acémilas se convirtió en los pies y manos del hombre andino, tanto para el traslado de carga como para las cabalgatas que aproximaron las estancias y las comunidades interandinas o también para las grandes cabalgatas en los Andes. Sin embargo, la variedad de caballos "chuscos" o más pequeños son los que se adaptaron a las condiciones del frío y a la escasez del forraje altoandino, algo similar a los camélidos, y éstos, a su vez, sufrieron un proceso de despoblamiento por la mala atención y marginación y recién en las últimas décadas se le dio importancia por su fibra, como una salida a la economía deprimente del campesinado. Mientras los mejores caballos, altos y de "raza", son de los valles y están relacionados con la casta dominante o gobernante (gamonalismo) y hoy con la gente pudiente vinculada a la red del poder local y regional; además, los campesinos de modesta condición son conscientes de que los "mejores caballos" tienen un alto costo y riesgo y no son adecuados para la crianza por su delicadeza; es decir, si es que no son bien atendidos o alimentados se enferman o mueren antes de tiempo, mientras los "chuscos" o criollos se adaptan a la condición deprimente de la pobreza comunal y a la inclemencia del tiempo y espacio andino y, sobre todo, en los mejores o malos tiempos, en las alturas como en la qechwa yunga no dejan de ser compañeros de trabajo, como reza el siguiente dicho: "las acémilas son muy serviciales a toda hora y en todo lugar, no se queja ni se cansa, siempre está contigo".

Entonces, esa condición fue abstraída, subjetivada e invertida por la aspiración al progreso y del poder en la figura del apu poderoso y justiciero que recorre el mundo en su mejor y brioso caballo, para beneficiar o castigar según la conducta ritual y social de las gentes de su jurisdicción. De este modo, también se invierte la condición original del caballero "Santiago Mataindios" al caballero "Apu justiciero y defensor de los indios". Lo que indica que el caballo fue configurado en el símbolo de poder y prestigio en los Andes, vinculado a la propiedad de la tierra. Y con el tiempo, como efecto de la mundialización y de las reglas de la economía de mercado, seguramente también los apus conducirán los mejores "Hi-Lux" de 4x4, "Volvos", "Mercedes" o los "Ferrari", símbolos del poder de la economía industrial y financiera del mundo globalizante.

Aunque, contradictoriamente a esta perspectiva, doña Honorata testimoniaba la condición de vida y economía campesina de su espacio, cuando dice: "Antes había más 
agua y se comía bien para estar sano y fuerte, ahora ya no hay ni aliento y estamos más decaídos, sin ganas y viejos desde joven". Con esta comparación, también recordó que en otros tiempos, cuando era jovencita, la fiesta era mejor y alegre y todavía recuerda algunas canciones y sucesos de antaño en alusión al origen de los ganados, como nos ilustra con el siguiente relato explícito:

"Las vacas vinieron de España y las llamas son del Perú. Las vacas son comidas sólo por los doctores o presidentes o por las gentes pudientes, y nosotros comemos aquí sólo la carne de llama o del paqo. También, las ovejas y los cerdos fueron traídos por mamacha Santa Elena y Santa Teresa, quienes como hermanas se animaron en conocer el Perú; por eso decían los abuelos, que también las vacas lloraban (mugían) en España mirando la dirección del Perú. Pues antes poseyeron sólo los hermanos Oncivil y Crucivil, como únicos dueños en España. Y como las mamachas (las vírgenes) conocieron el Perú, retornaron para que San Marcos, San Felipe y San Lucas trajeran las vacas, los tres llegaron jalando las vacas y ellos son los patrones de los vacunos. San Marcos trajo las vacas moras (pillka) y jaspiadas (huska), aunque la pillka se regresó y por eso, aquí en Huancavelica los vacunos en su mayoría son de color husko.

Después vino Santiago trayendo los ganados y en el trayecto descansó en una pampa grande, debajo de un cerro bien alto. Y fue Santiago quien inició la fiesta del vacuno. Santiago habría sido una persona como nosotros y vino a pasearse arreando sus ganados como en comparsa, tomando su trago. Por eso, también nosotros celebramos con fiesta y alegría para que ellos (los santos) se alegren como han querido que sea".

De este modo, el "Tayta Santiago" es patrón de los ganados vacunos traídos de España y, es más, simbólicamente explicita que la fiesta del ganado vacuno es un rito importado al mundo andino, la conquista y colonización del mundo andino no sólo fue la apropiación de sus diferentes recursos naturales, sociales y culturales, sino también fue la inmigración y desplazamiento de una densa masa colonizadora de amparadores de las mejores tierras del mundo conquistado, que arribaron con todo su aparato cultural y valores espirituales para su respectiva adaptación en el nuevo espacio cultural, dentro de la sintonía políticoadministrativa de la burocracia del Estado colonial y del aparato exitoso de la iglesia, como inculcadores y sustentadores de la tradición hispana. Esto explica las diferencias y preferencias en representaciones y festejos de las deidades por el poblador altoandino o "sallqa" (puna) de origen precolombino y de la parte baja o qechwa (zona templada o yunga) de origen colonial.

De similar forma, Taipe (1991) señala las características de Santiago como un santo negociante que llegó a Colcabamba (Tayacaja, Huancavelica) desde España y por dormilón fue aventajado por "Tayta San Juan", por lo que le festejan los 24 de junio y a "Tayta Santiago" los 25 de julio. Choy (1987) indica la utilización con celo la victoria de Santiago contra el Islam, como el "salvador del indio" contra los incas y del demonio (homologándose a los prestigios del "Illapa"), para que los nativos no reutilicen ese símbolo contra los propios "chapetones", como habría sucedido en Lircay en las postrimerías de la colonia (Pease, 1974) o hayan tenido similar sensación los nativos de Yucatán (México) de que "Dios les ordenó a los indígenas proseguir luchando contra los ladinos" (Reifler, 1989: 202) blancos a través de Juan de la Cruz, en 1851, o que un líder de los zinacantecos y chamulas "... exhortaba a sus hermanos de raza a reconocer una imagen de la Virgen que emitía rayos de luz, y que, decía, había descendido del Cielo para ayudar a los indígenas" (Reifler, 1989: 113).

Mientras Fuenzalida (1979 y 1980) analiza la estructura de los mitos, ritos y la representación de los personajes de la fiesta del ganado en Moya y muestra que la 
veneración a Santiago enmascara al verdadero culto de los apus. Asimismo, diremos que también muchos mistis de las antiguas haciendas de la zona de Acobamba reconocieron el prestigio de los apus y sus siervos cumplieron la función de oferentes y a su vez ostentaron la categoría de "Wiraqochas"; por tanto, en la simbología del poder y prestigio, la severa autoridad de los apus fue homologable a la autoridad y mando de los señores mistis y hoy a las gentes con poder en la ciudad capital de la región o de Lima.

\section{Bibliografía}

ALBERT-LLORCA, Marlene y José GONZÁLEZ (Comp)

2003 Moros y cristianos. Centro de Investigaciones Etnológicas Ángel Ganivet, Granada.

ARROYO, Sabino

2006 "Formas de vida e integración de los afroperuanos de hoy". En Investigaciones Sociales $\mathrm{N}^{\circ}$ 16. pp.17-50. Instituto de Investigaciones Histórico Sociales, UNMSM, Lima.

2008 El culto a los Hermanos Cristo: Sistema religioso andino y cristiano: Redes y formas culturales del poder en los Andes. UNMSM, Lima.

2004 Dioses y oratorios andinos de Huancabamba. Fondo Edit. UNMSM, Lima.

1987 Algunos aspectos del culto al Tayta Wamani. UNMSM, Lima

CARO BAROJA, Julio

1985 Las formas complejas de la vida religiosa (siglos XVI y XVII). Ed. Sarpe, Madrid

CALANCHA, Antonio de la

1977 Crónicas del Perú. Lima, Ediciones del Ignacio Prado

CHOCANO, Magdalena

1983 "Circuitos comerciales y auge minero en la sierra central". En Allpanchis 1983: $3-26, \mathrm{~N}^{\circ} 21$, Cusco

CHOY, Emilio

1987 Antropología e historia $\mathrm{N}^{\circ}$ 1. UNMSM, Lima

CUSTRED, Glynn

1977 "Las punas de los andes centrales". En J. Flores 1977: 55-86, IEP, Lima

ELIADE, Mircea

1968 Mito y realidad. Edic. Guadarrama, S.A., Madrid

FUENZALIDA, Fernando

1979 "El Cristo pagano de los Andes: una cuestión de identidad". En Debates N$^{\circ} 4$, 1979: 1-10, PUCP, Lima.

1980 "Santiago y el Wamani: aspectos de un culto pagano en Moya". En Debates № 5 , 1980: 155-188, PUCP, Lima

FLORES, Jorge (Comp.)

1977 Pastores de puna. IEP, Lima

GADE, Daniel

1977 “Llama, alpaca y vicuña: ficción y realidad". En Flores 1977: 113-120, IEP, Lima

GUAMAN POMA DE AYALA, Phelipe

1980 Nueva corónica y buen gobierno. Siglo XXI/IEP, México 
HERNÁNDEZ, Harold

2006 "El trayecto de Santiago Apóstol de Europa al Perú" (51-92). En Investigaciones Sociales $\mathrm{N}^{\circ}$ 16. Instituto de Investigaciones Histórico Sociales. Facultad de Ciencias de la UNMSM, Lima.

HUMBOLDT, Alejandro de

1973 “Cajamarca1802”. En E. Nuñez: El Perú visto por los viajeros, Tomo II, Edic. Peisa, Lima

MANRIQUE, Nelson

1983 "Los arrieros de la sierra central durante el siglo XIX". En Allpanchis $\mathrm{N}^{\circ} 21,27-$ 46, Cusco

MOROTE, Efraín

1988 Aldeas sumergidas. Bartolomé de las Casas, Cusco

PEASE, Franklin

1974 “Un movimiento mesiánico en Lircay, Huancavelica (1811). En Revista del Museo Nacional $\mathrm{N}^{\circ}$ 40, 1974: 221-252, Lima

PORTOCARRERO, Gonzalo y Jorge Komadina

2001 Modelos de identidad y sentidos de pertenencia en Perú y Bolivia. IEP, Lima

QUIJADA, Sergio

1985 Estampas huancavelicanas. Lima

RAYMONDI, Antonio

1956 El Perú. Lima

REIFLER, Victoria

1989 El cristo indígena, el rey nativo. FCE, México

RIVA-AGUERO, José de la

1960 Afirmación del Perú. Instituto Riva-Agüero, Lima

ROSTWOROWSKI, María

1992 Pachacamac y el Señor de los Milagros. Lima, IEP

URRUTIA, Jaime

1983 "De las rutas, ferias y circuitos en Huamanga". En Allpanchis N 21, 47-64 Cusco

VALDERRAMA, Ricardo y Carmen Escalante

1983 “Arrieros, troperos y llameros de Huancavelica". En Allpanchis N²1, 65-88, Cusco 